\title{
Estimation of geomagnetically induced currents based on the measurement data of a transformer in a Japanese power network and geoelectric field observations
}

\author{
Shinichi Watari
}

\begin{abstract}
Geomagnetically induced currents (GICs) have the potential to cause electric power blackouts. Hence, it is important to study the effects of GICs produced by intense geomagnetic storms. The measurements of GICs were conducted at the Memanbetsu substation, Hokkaido, between December 2005 and March 2008. We obtain the complementary cumulative distribution function (CCDF) of the measured GICs and the empirical equation to estimate GICs using the GIC data and geoelectric field observation data. GICs associated with the past intense geomagnetic storms, e.g., the March 13-15 storm and the October 29-30, 2003 storm, are estimated.
\end{abstract}

Keywords: Geomagnetically induced current (GIC); Geomagnetic storm; Geoelectric fields; Space weather

\section{Background}

The effects of geomagnetically induced currents (GICs) on electric power grids have been observed since the 1940s (Boteler 2001). An electric power blackout occurred in Quebec, Canada, during the March 13-15, 1989 storm (Boteler et al. 1989; Kappenman 1989; Boteler 2001). In southern Sweden, the GIC caused an electric power blackout on October 30, 2003 (Kappenman 2005).

The occurrence of strong GICs is often associated with strong auroral electrojet currents at geomagnetically high latitudes (Thomson et al. 2011; Pulkkinen et al. 2012). Japan is located at a geomagnetically lower latitude compared to its geographical latitude. It is believed that the possibility of power grid problems caused by GICs is lower because of the country's location at geomagnetically low latitude. However, it was reported that long distance telegraph lines between Tokyo and the regions outside Tokyo (the Tokyo-Yokkaichi line, the Tokyo-Matsumoto line, the Tokyo-Ogasawara line, the Tokyo-Guam line, and so on) were affected by GICs caused by a geomagnetic storm on September 25, 1909 in Japan (Uchida 1909). Kappenman (2004) noted that

Correspondence: watari@nict.go.jp

National Institute of Information and Communications Technology, 4-2-1 Nukuikita, Koganei, Tokyo 184-8795, Japan large GICs are produced by geomagnetic disturbances driven by the intensification of the ring and magnetopause currents at low latitudes. Gaunt and Coetzee (2007) reported damage to transformers caused by GICs in South Africa as a result of series of intense geomagnetic storms between the end of October and the beginning of November in 2003. The geomagnetic latitude of South Africa is similar to that of Japan. This suggests a possibility of GIC effects in countries with lower geomagnetic latitudes such as Japan if an extremely large geomagnetic storm, such as the Carrington storm on September 1-2, 1859, occurs (Watari et al. 2001; Tsurutani et al. 2003; Committee on the Societal and Economic Impacts of Severe Space Weather Events 2008; The working group on extreme solar weather of the Royal Academy of Engineering 2013). Pulkkinen et al. (2012) and Bernabeu (2013) made studies on extreme 100 -year geoelectric field scenarios. In Spain located in low geomagnetic latitude, Torta et al. (2014) studied the effect of GICs on the Spanish high-voltage power network.

In a Japanese power network, GIC measurements were conducted between December 2005 and March 2008 as part of the close collaboration among National Institute of Information and Communications Technology (NICT), 


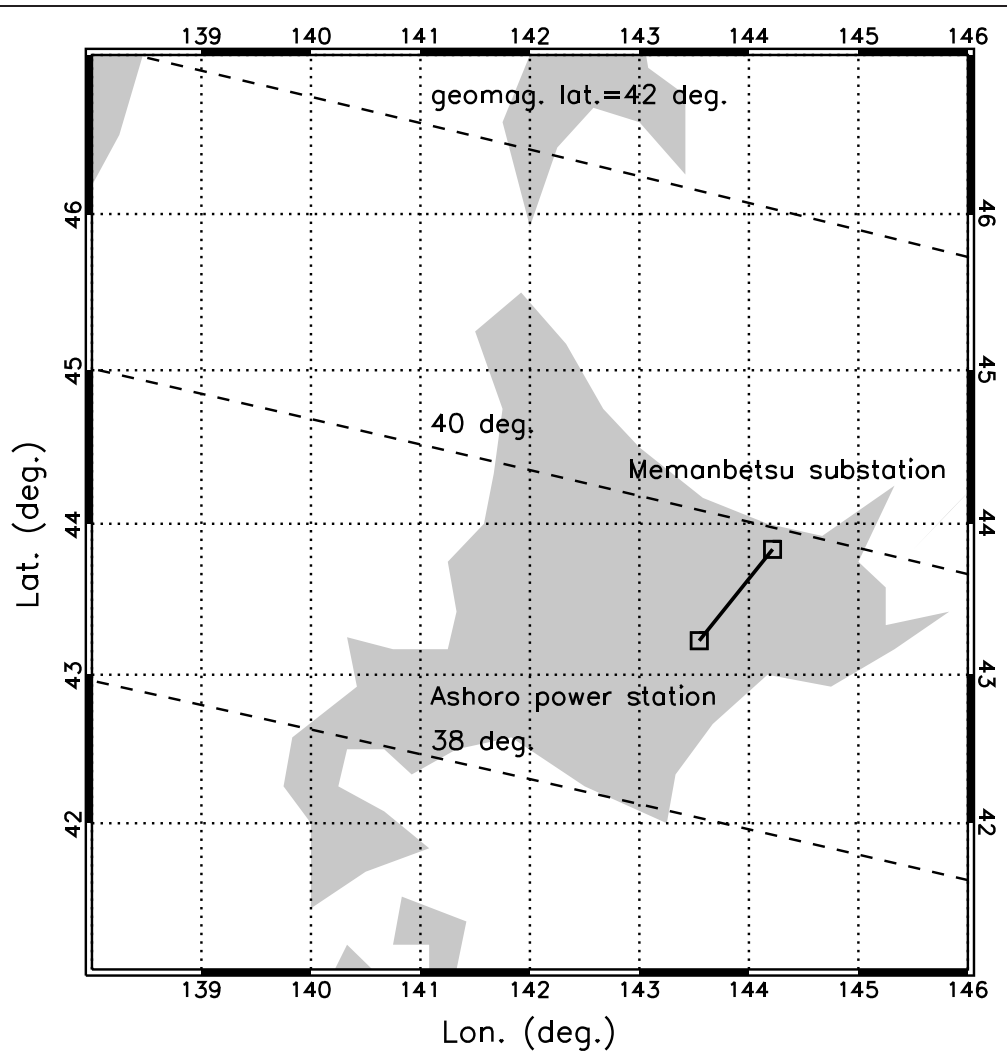

Fig. 1 Configuration of 187-kV power line of GIC measurements

Hokkaido Electric Power Co., and Solar-Terrestrial Environment Laboratory (STEL) at Nagoya University (Watari et al. 2009). We obtained the empirical equations of GICs using the GIC measurement data and geoelectric field data and estimated GICs associated with the past intense geomagnetic storms.

\section{Methods}

\section{Data}

Using a current clump meter, we measured the electrical current of a grounded neutral point of a transformer at the Memanbetsu substation of the Hokkaido Power Co. between December 2005 and March 2008. The transformer is an ordinal three-phase transformer and is connected to the $187-\mathrm{kV}$ line from the Ashoro power station as shown in Fig. 1. Both ends of the line are grounded and the Memanbetsu substation is an end point of this line. There is no branch between Memanbetsu and Ashoro. The line is in a south-west direction (approximately $40^{\circ}$ west-wards from the north-south direction) and the length of the line is approximately $100 \mathrm{~km}$. To analyze the 1-s GIC data, we used 1-s geomagnetic field data and the 1-s and 1-min geoelectric field data at the Memanbetsu Observatory, Japan Meteorological Agency (JMA), near the substation. The 1-hour geomagnetic field data since 1958 are also used for a statistical analysis. The geoelectric fields are measured by potential difference between two electrodes separately buried in the ground.

Table 1 Large GIC events measured between December 2005 and March 2008

\begin{tabular}{llll}
\hline Number & Date and time $(\mathrm{UT})$ & Max. GIC of 1-s data $(\mathrm{A})$ & Geomagnetic disturbances at Memanbetsu \\
\hline 1 & 14 December 2006 at 23:55 & 3.85 & SC storm (max. $\Delta H=272 \mathrm{nT})$ \\
2 & 10 November 2006 around 10:04 & 2.23 & Gradual storm (max. $\Delta H=143 \mathrm{nT})$ \\
3 & 23 May 2007 at 10:40 & 1.81 & Positive bay \\
4 & 30 November 2006 around 09:09 & 1.75 & Gradual storm (max. $\Delta H=108 \mathrm{nT})$ \\
5 & 9 July 2006 at 21:39 & 1.59 & Sudden impulse \\
6 & 14 April 2006 around 10:15 & 1.58 & Gradual storm (max. $\Delta H=157 \mathrm{nT})$ \\
7 & 19 August 2006 around 14:22 & 1.52 & Gradual storm (max. $\Delta H=103 \mathrm{nT})$ \\
\hline
\end{tabular}

SC sudden commencement 

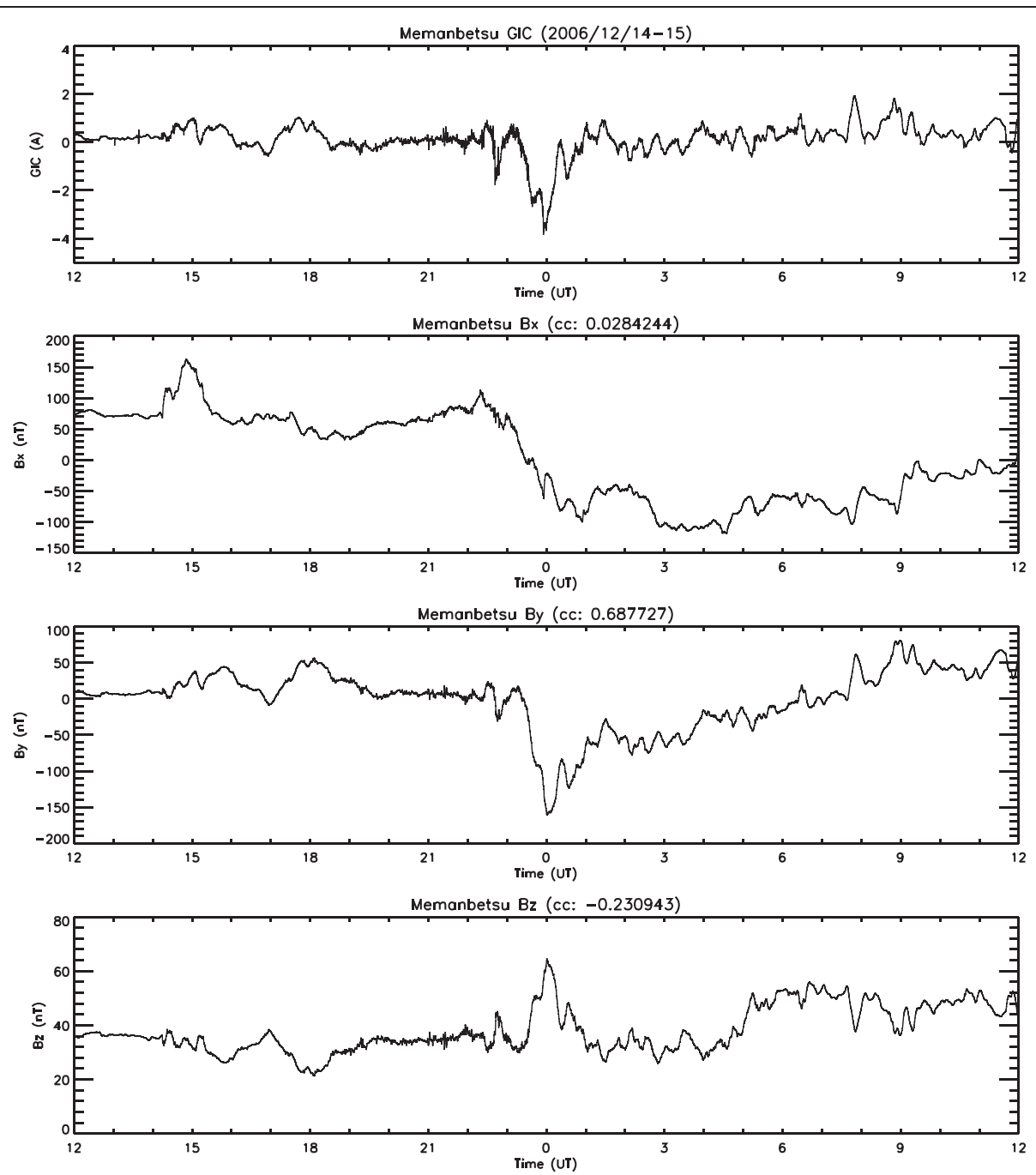

Fig. 2 GIC associated with the geomagnetic storm on December 14-15, 2006 (top panel) and geomagnetic field observation (Bx (second panel), By (third panel), and Bz (bottom panel)) at the Memanbetsu Observatory

Mean values of the data sets are subtracted to remove the offsets of the geoelectric field data in this paper.

\section{Results and discussion}

\section{Observed GICs in Hokkaido}

Table 1 presents a list of the large GICs observed during the period of our GIC measurements with geomagnetic disturbances observed at the Memanbetsu Observatory. The GIC events in Table 1 are associated with geomagnetic storms with the exception of two events, a positive bay and a sudden impulse (SI) event. GICs associated with positive bays, auroral activities in high latitude, are often observed in our measurements (Watari et al. 2009). We show two examples of observed GICs at the Memanbetsu substation associated with the geomagnetic storms with variations of geomagnetic fields at the Memanbetsu Observatory.
Figure 2 shows the GIC event associated with a geomagnetic storm on December 14-15, 2006. This geomagnetic storm was caused by a full halo coronal mass ejection (CME) on December 13, 2006. Magnetic and geoelectric fields observed at the Memanbetsu Observatory are also shown with the GIC data. According to this figure, temporal variations of By, east-west component of geomagnetic fields, show a good correlation with the measured GIC data. The maximum 1-s GIC value of $3.85 \mathrm{~A}$ is measured during the main phase of the storm.

Figure 3 shows the GICs and geomagnetic fields of the November 9-11, 2006 storm. This storm was caused by high-speed solar wind from a coronal hole and started gradually. As shown in Fig. 3, the maximum 1-s GIC value of 2.23 A measured around 10:00 UT associated with a large variation of By component of geomagnetic 

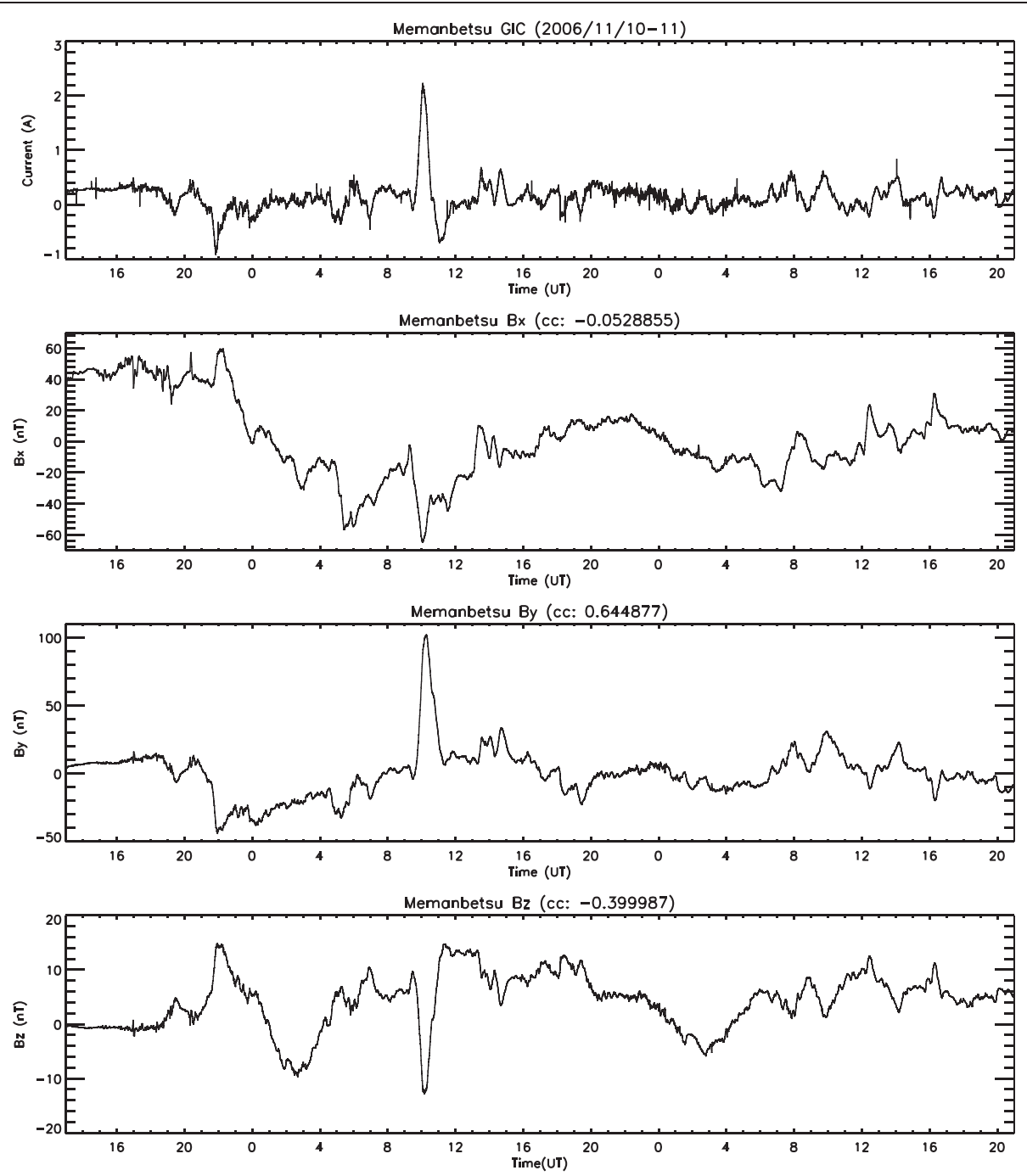

Fig. 3 GIC associated with the geomagnetic storm on November 9-10, 2006 (top panel) and geomagnetic field observation (Bx (second pane), By (third panel), and Bz (bottom panel)) at the Memanbetsu Observatory

fields during the storm. Several spikes of the GIC data in Figs. 2 and 3 are artificial noises.

\section{Probability occurrence of GICs and electric field observation}

There are several methods to estimate the probability of occurrence of the extreme space weather events (Hapgood 2011; Love 2012; Riley 2012; Kataoka 2013). Here, we used a method shown by Riley (2012) and Kataoka (2013) to estimate the probability of occurrence of the events exceeding some critical value. Probability of an event of magnitude equal to or greater than some critical values $x_{\text {crit }}$ is expressed below.

$$
P\left(x \geq x_{\text {crit }}\right)=\int_{x_{\text {crit }}}^{\infty} p\left(x^{\prime}\right) d x^{\prime}
$$

This is called the complementary cumulative distribution function (CCDF). If the probability of occurrence, $p(x)$ follows a power law distribution:

$$
p(x)=C x^{-\alpha}
$$

Equation 1 is expressed by the equation below.

$$
P\left(x \geq x_{\text {crit }}\right)=\frac{C}{\alpha-1} x_{\text {crit }}^{-\alpha+1}
$$

where $\alpha$ and $C$ are some fixed values.

The Poisson distribution is applicable for the probability of occurrence of one or more events equal to or greater than $x_{\text {crit }}$ during some time $\Delta t$ assuming the events occur independently of one another. The probability of in $\Delta t$ is given by the equation below. 

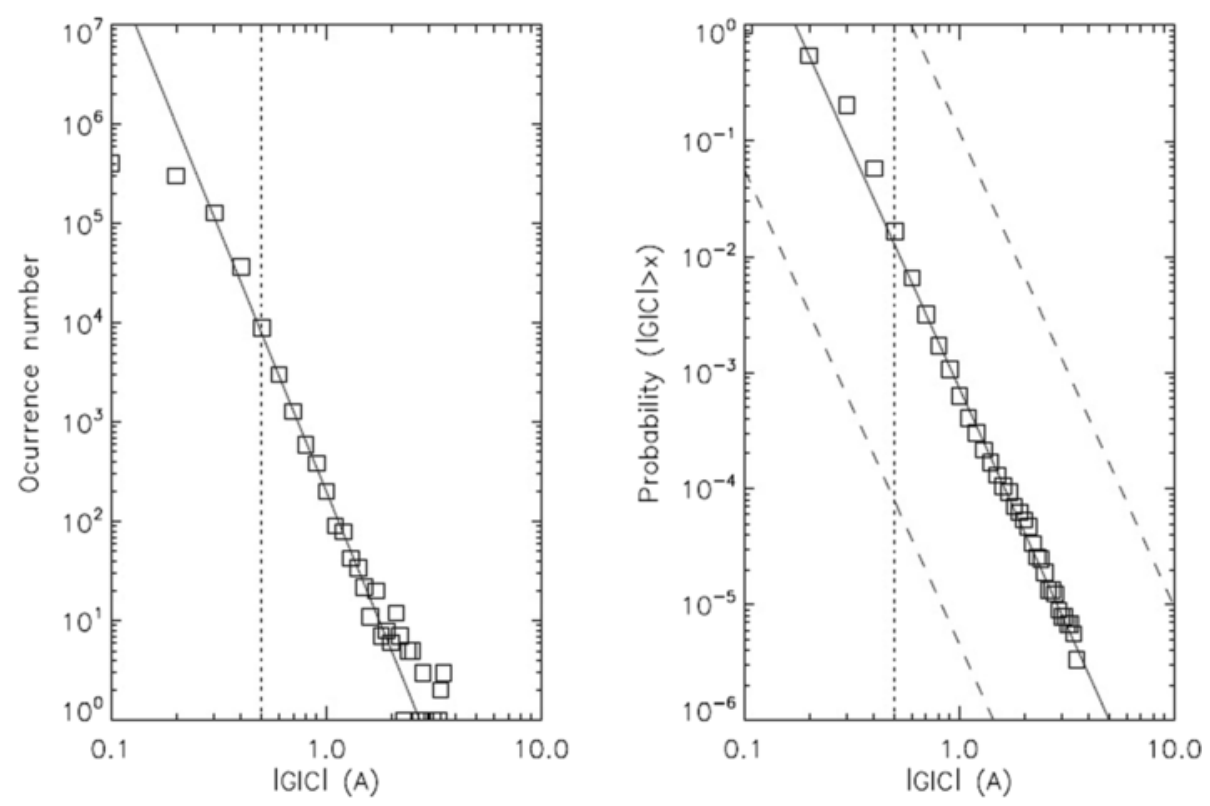

Fig. 4 Occurrence number of 1-min averaged values of GICs and the CCDF of the values equal to or greater than $0.1 \mathrm{~A}$. The dashed lines in the right panel show $95 \%$ confidence interval of the fitting (solid line)

$$
P\left(x \geq x_{\text {crit }}, t=\Delta t\right)=1-e^{-N \frac{\Delta t}{\tau} P\left(x \geq x_{\text {crit }}\right)}
$$

where $N$ is the number of events in the data set and $\tau$ is the total time span of the data set.

Figure 4 shows occurrence number of 1-min averaged values of the GIC data between December 2005 and March 2008 and the CCDF of the values equal to or greater than GIC values of the horizontal axes. Two dashed lines show $95 \%$ confidence interval. There is a power law relation for the value equal to or greater than 0.5 A (see the vertical dotted line in Fig. 4). Hence, $N$ becomes the number of events equal to or greater than $0.5 \mathrm{~A}$. The exponent value of $\alpha$ of 5.11 and the value of $C$ of 0.0030 are obtained by using the data in Fig. 4. We can calculate the probability using Eq. 3. For example, the probability with $95 \%$ confidence interval of GIC value equal to or greater than $10 \mathrm{~A}$ is $5.8 \times 10^{-8}[3.5 \times$ $10^{-10}, 9.5 \times 10^{-6}$ ]. The probability of GIC $\geq 100 \mathrm{~A}$ is
$4.5 \times 10^{-12}\left[2.6 \times 10^{-14}, 7.8 \times 10^{-10}\right]$. According to Eq. 4, the probabilities with $95 \%$ confidence interval of $\mathrm{GIC} \geq 10 \mathrm{~A}$ in 50 and 100 years are 0.67 [0.0067, $1.0]$ and $0.89[0.013,1.0]$, respectively. And the probabilities of GIC $\geq 100 \mathrm{~A}$ in 50 and 100 years are $8.7 \times$ $10^{-5}\left[5.0 \times 10^{-7}, 1.4 \times 10^{-2}\right]$ and $1.7 \times 10^{-4}\left[1.0 \times 10^{-6}\right.$, $\left.2.9 \times 10^{-2}\right]$, respectively.

Intense GICs are produced by large geoelectric fields. Hence, we study the 1-min geoelectric field data at the Memanbetsu Observatory near the substation between 1987 and 2014. Table 2 shows dates and geomagnetic disturbances when the largest geoelectric fields more than or equal to $0.1 \mathrm{~V} / \mathrm{km}$ are observed. They are observed or associated with intense geomagnetic storms as shown in Table 2. Figure 5 shows the occurrence number and the CCDF of the values equal to or greater than geoelectric field values of horizontal axes. There is a power law relation for the value equal to or greater than

Table 2 Largest geoelectric fields observed between 1958 and 2014 at the Memanbetsu Observatory

\begin{tabular}{|c|c|c|c|}
\hline Number & Date and time (UT) & Max. |E| of 1-min data (V/km) & Geomagnetic disturbances at Memanbetsu \\
\hline 1 & 13 March 1989 at 21:58 & 0.184 & SC storm (max. $\Delta H=747 \mathrm{nT})$ \\
\hline 2 & 8 November 1991 at 22:17 & 0.137 & SC storm (max. $\Delta H=392 \mathrm{nT})$ \\
\hline 3 & 29 October 2003 at 19:54 & 0.123 & SC storm (max. $\Delta H=513 \mathrm{nT})$ \\
\hline 4 & 30 October 2003 at 19:54 & 0.120 & SC storm (max. $\Delta H=467 \mathrm{nT})$ \\
\hline 5 & 14 March 1989 at 00:03 & 0.115 & SC storm (max. $\Delta H=747 \mathrm{nT})$ \\
\hline 6 & 15 July 2000 at $21: 36$ & 0.115 & SC storm (max. $\Delta H=520 \mathrm{nT})$ \\
\hline 7 & 24 March 1991 at 04:02 & 0.115 & SC storm (max. $\Delta>467 \mathrm{nT})$ \\
\hline 8 & 6 November 2001 at 02:02 & 0.104 & $\mathrm{SC}$ storm (max. $\Delta H=338 \mathrm{nT})$ \\
\hline
\end{tabular}

SC sudden commencement 

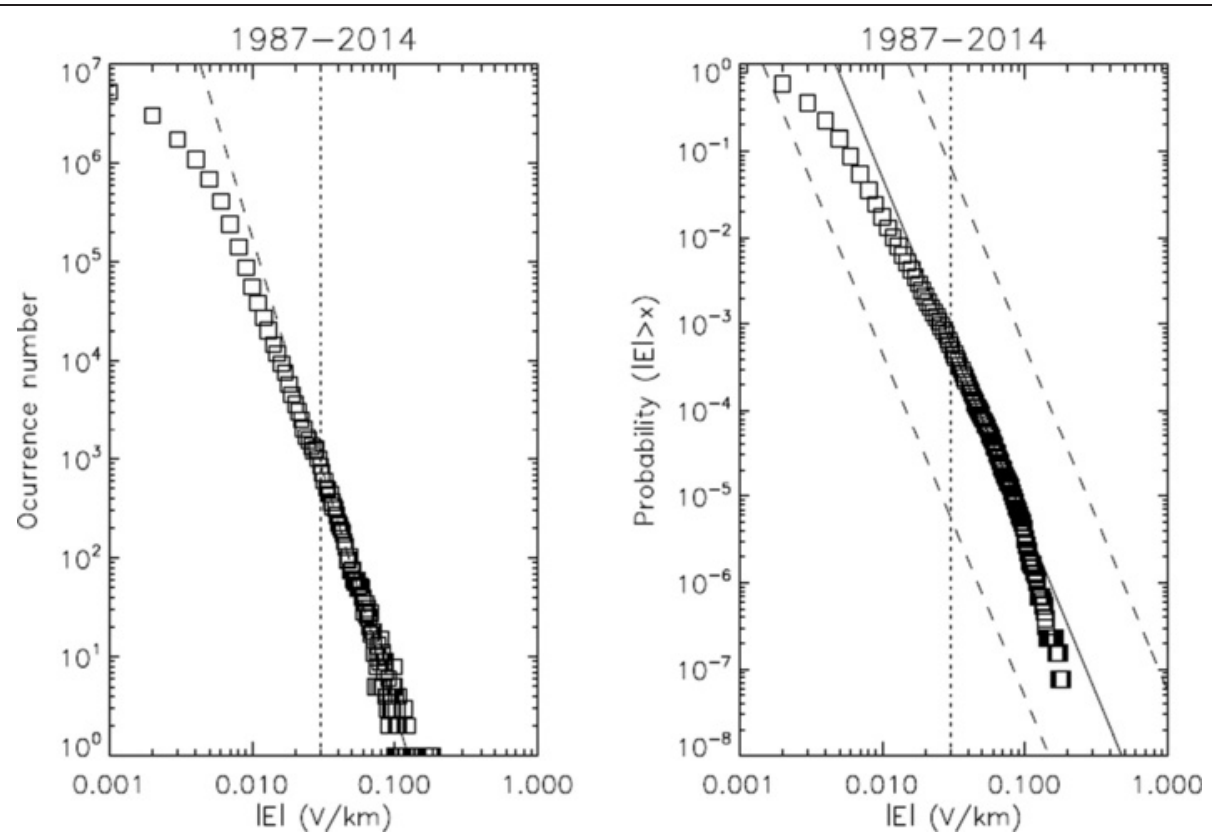

Fig. 5 Occurrence number of 1-min values of geoelectric field data between 1987 and 2014 at the Memanbetsu Observatory and the CCDF of the values equal to or greater than $0.001 \mathrm{~V} / \mathrm{km}$. The dashed lines in the right panel show $95 \%$ confidence interval of the fitting (solid line)

$0.03 \mathrm{~V} / \mathrm{km}$ (see the vertical dotted line in Fig. 5) and $N$ is the number of data equal to or greater than $0.003 \mathrm{~V} /$ $\mathrm{km}$. The exponent value of $\alpha$ of 4.98 and the value of $\mathrm{C}$ of $2.11 \times 10^{-9}$ are obtained by using the data in Fig. 5 . The probability with $95 \%$ confidence interval of geoelectric fields $|\mathrm{E}|$ equal to or greater than $1.0 \mathrm{~V} / \mathrm{km}$ is $5.3 \times 10^{-10}$ $\left[4.9 \times 10^{-12}, 5.7 \times 10^{-8}\right]$ and that of $|\mathrm{E}| \geq 5.0 \mathrm{~V} / \mathrm{km}$ is $8.7 \times$ $10^{-13}\left[8.1 \times 10^{-15}, 9.3 \times 10^{-11}\right]$. Using Eq. 4, the probabilities of $|\mathrm{E}| \geq 1.0 \mathrm{~V} / \mathrm{km}$ in 50 and 100 years are $1.2 \times 10^{-2}$ $\left[1.1 \times 10^{-4}, 7.3 \times 10^{-1}\right]$ and $2.4 \times 10^{-2}\left[2.3 \times 10^{-4}, 9.3 \times\right.$
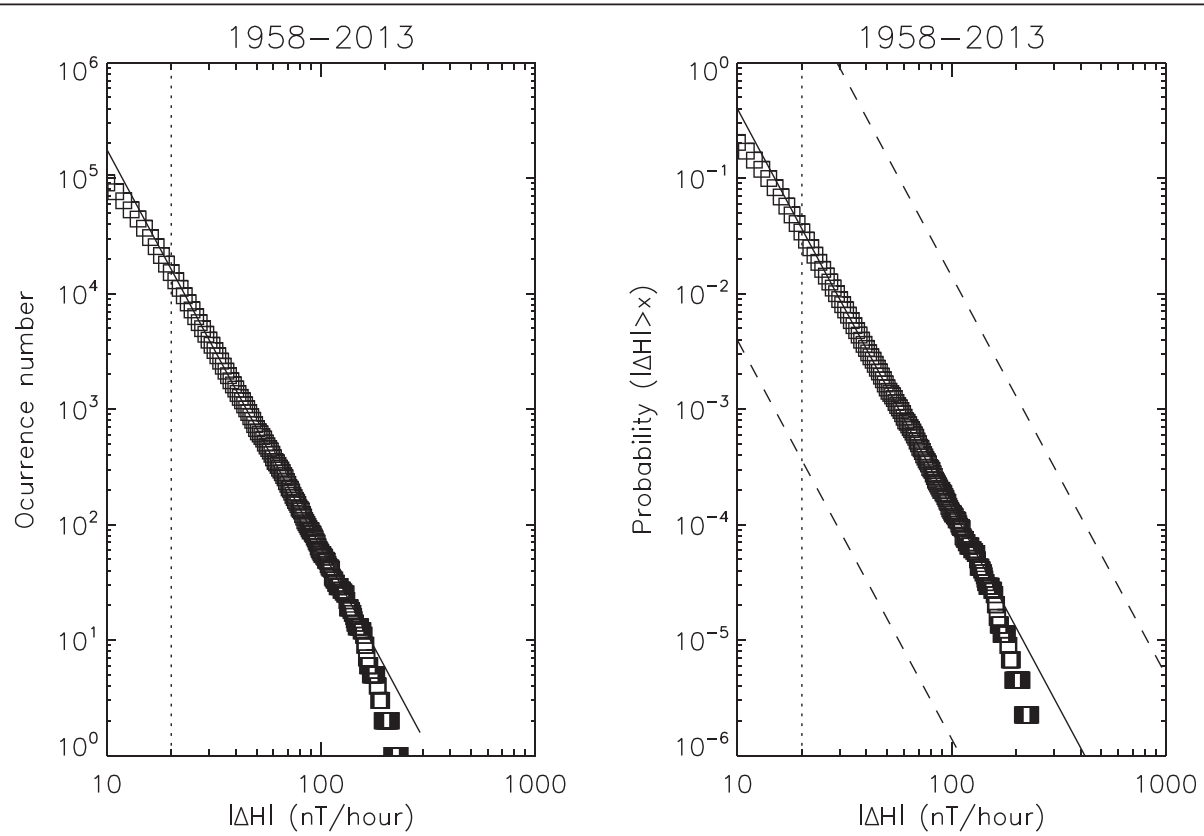

Fig. 6 Occurrence number of absolute values of difference of 1-hour values of horizontal component of Memanbetsu geomagnetic field data between 1958 and 2013 and the CCDF of the values equal to or greater than 10 nT/hour. The dashed lines in the right panel show $95 \%$ confidence interval of the fitting (solid line) 

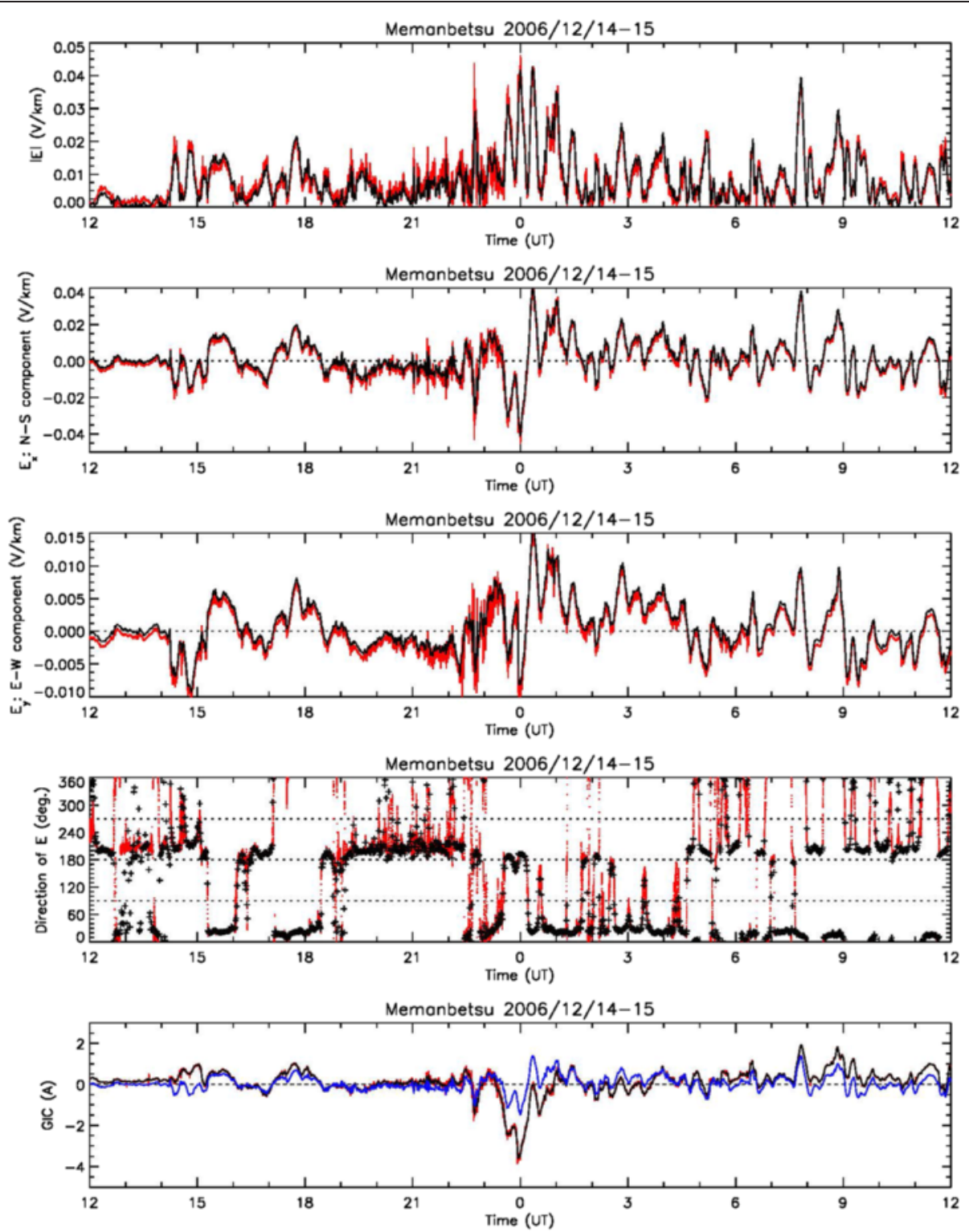

Fig. 7 Geoelectric fields observed at the Memanbetsu Observatory with the GIC data of the December 14-15, 2006 storm. Angle is $0^{\circ}$ for the north and increases clockwise. Block lines and crosses show the 1-min data, and red lines and dots in the figure show the 1-s data. The blue line is the estimated GIC using the 1-min geoelectric field data

$10^{-1}$, respectively. The probabilities of $|\mathrm{E}| \geq 5.0 \mathrm{~V} / \mathrm{km}$ in 50 and 100 years are $2.0 \times 10^{-5}\left[1.9 \times 10^{-7}, 2.2 \times 10^{-3}\right]$ and $4.0 \times 10^{-5}\left[3.7 \times 10^{-7}, 4.3 \times 10^{-3}\right]$, respectively.

One-hour geomagnetic field data of Memanbetsu Observatory are available since 1958. Figure 6 shows occurrence number and the CCDF of the values equal to or absolute values $|\Delta H|$ of difference of 1 hour values of horizontal component of Memanbetsu geomagnetic field greater than values of horizontal axes. There is a power law relation for the value equal to or greater than 20 $\mathrm{nT} /$ hour (see the vertical dotted line in Fig. 6). $N$ is the number of data equal to or greater than $20 \mathrm{nT} /$ hour.
The exponent value of $\alpha$ of 4.45 and the value of $C$ of $3.90 \times 10^{3}$ are obtained by using the data in Fig. 6 . The probability with $95 \%$ confidence interval of $|\Delta H|$ equal to or greater than $500 \mathrm{nT} /$ hour is $5.41 \times 10^{-7}\left[5.4 \times 10^{-9}\right.$, $5.5 \times 10^{-4}$ ]. Using Eq. 4, the probabilities of $|\Delta H| \geq 500$ $\mathrm{nT} /$ hour in 50 and 100 years are $1.9 \times 10^{-2}\left[2.1 \times 10^{-3}\right.$, $1.0]$ and $3.5 \times 10^{-1}\left[4.3 \times 10^{-3}, 1.0\right]$, respectively.

\section{Estimation of GIC and discussion}

According to Pulkkinen et al. (2007) and Torta et al. (2012), GIC at a site by geoelectric field is modeled by the equation 


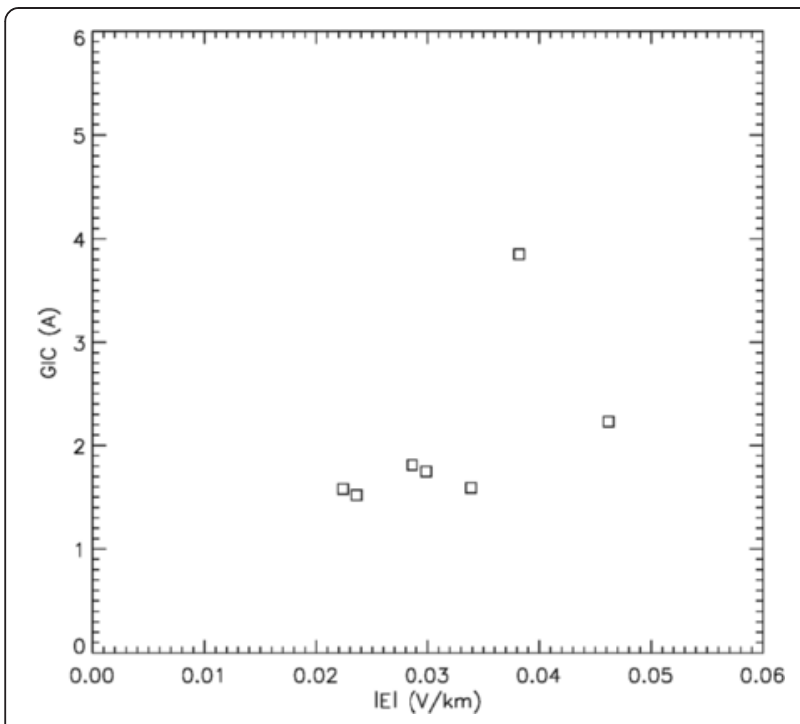

Fig. 8 One-s geoelectric field values associated GIC values shown in Table 1

$$
\mathrm{GIC}(t)=a E_{x}(\mathrm{t})+b E_{y}(t)+\varepsilon(t)
$$

where $E_{x}$ and $E_{y}$ are the horizontal components of the local geoelectric field and $a$ and $b$ are the site-dependent system parameters. $\varepsilon(t)$ is the noise term.

The values of $a$ and $b$ are given by the equations

$$
\begin{aligned}
& a=\frac{<\mathrm{GIC} E_{y}><E_{x} E_{y}>-<\mathrm{GIC} E_{x}><E_{y}^{2}>}{<E_{x} E_{y}>^{2}-<E_{x}^{2}><E_{y}^{2}>} \\
& b=\frac{<\mathrm{GIC} E_{x}><E_{x} E_{y}>-<\mathrm{GIC} E_{y}><E_{x}^{2}>}{<E_{x} E_{y}>^{2}-<E_{x}^{2}><E_{y}^{2}>}
\end{aligned}
$$

where $<$. > denotes the expectation taken over different realizations of the process.

Figure 7 shows geoelectric fields observed at the Memanbetsu Observatory with the GIC data of the December 1415, 2006 storm. In Fig. 7, north is $0^{\circ}$ and angle increases clockwise. The black lines and crosses show 1-min data and the red lines and dots show 1-s data. By applying the Eqs. 6 and 7 to the 1-min data in Fig. 7, values of $a$ and $b$ are obtained as 38.1 and $-7.4 \mathrm{~A} \mathrm{~km} / \mathrm{V}$, respectively. The blue line of Fig. 7 shows the estimated GIC using Eq. 5. The estimated value of GIC is approximately half of the observed value around the maximum of GIC in Fig. 7. Ogawa (2002) noted that it is necessary to consider a gain factor between the electric field at a site and the regional electric field. The gain factor is assumed to be 1 in the analysis of this paper. Figure 8 shows the 1-s geoelectric field values associated with the GIC values shown in Table 1. According to this figure, the GIC of the December 14-15, 2006 event, 3.85 A, is larger comparing with other events.

Vertical component of geomagnetic variation at a site is expressed by linear combination of the two horizontal
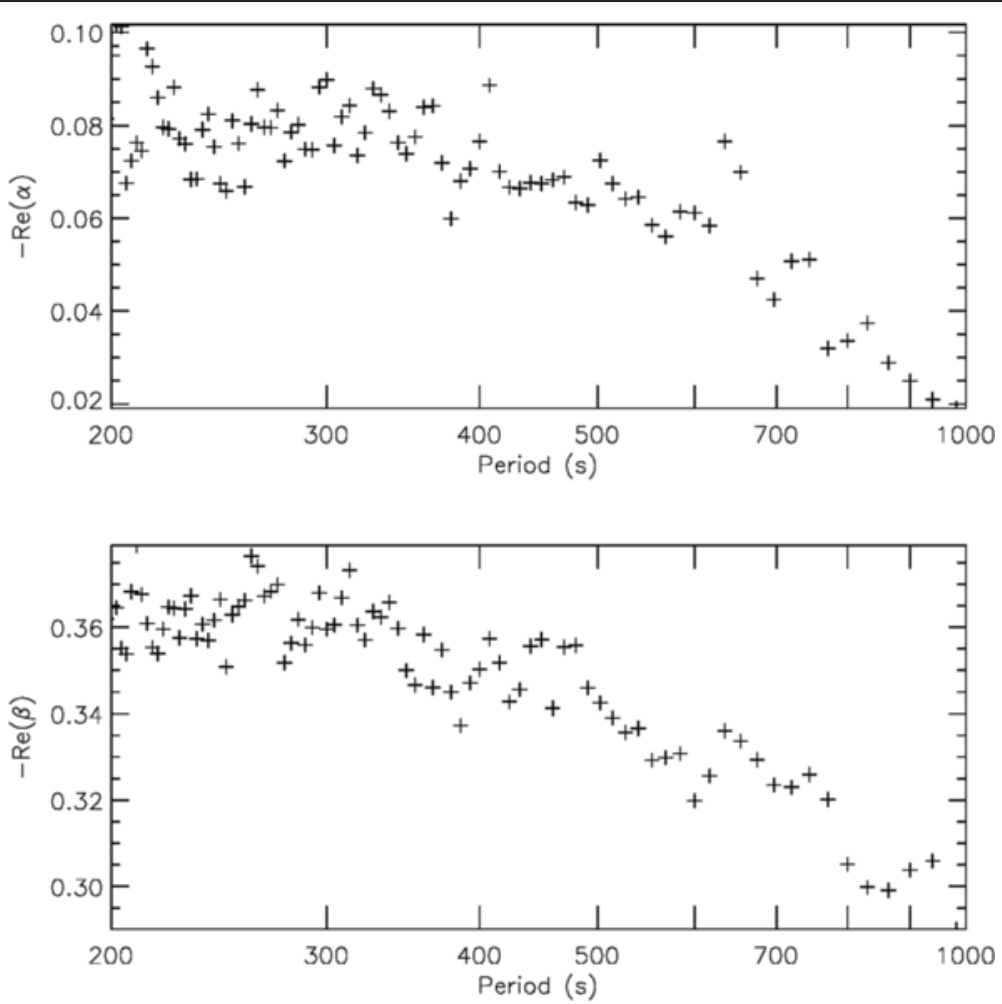

Fig. 9 Values of Parkinson arrow $(-\operatorname{Re}(\alpha),-\operatorname{Re}(\beta))$ for several frequencies calculated for Memanbetsu geomagnetic filed data shown in Fig. 2 

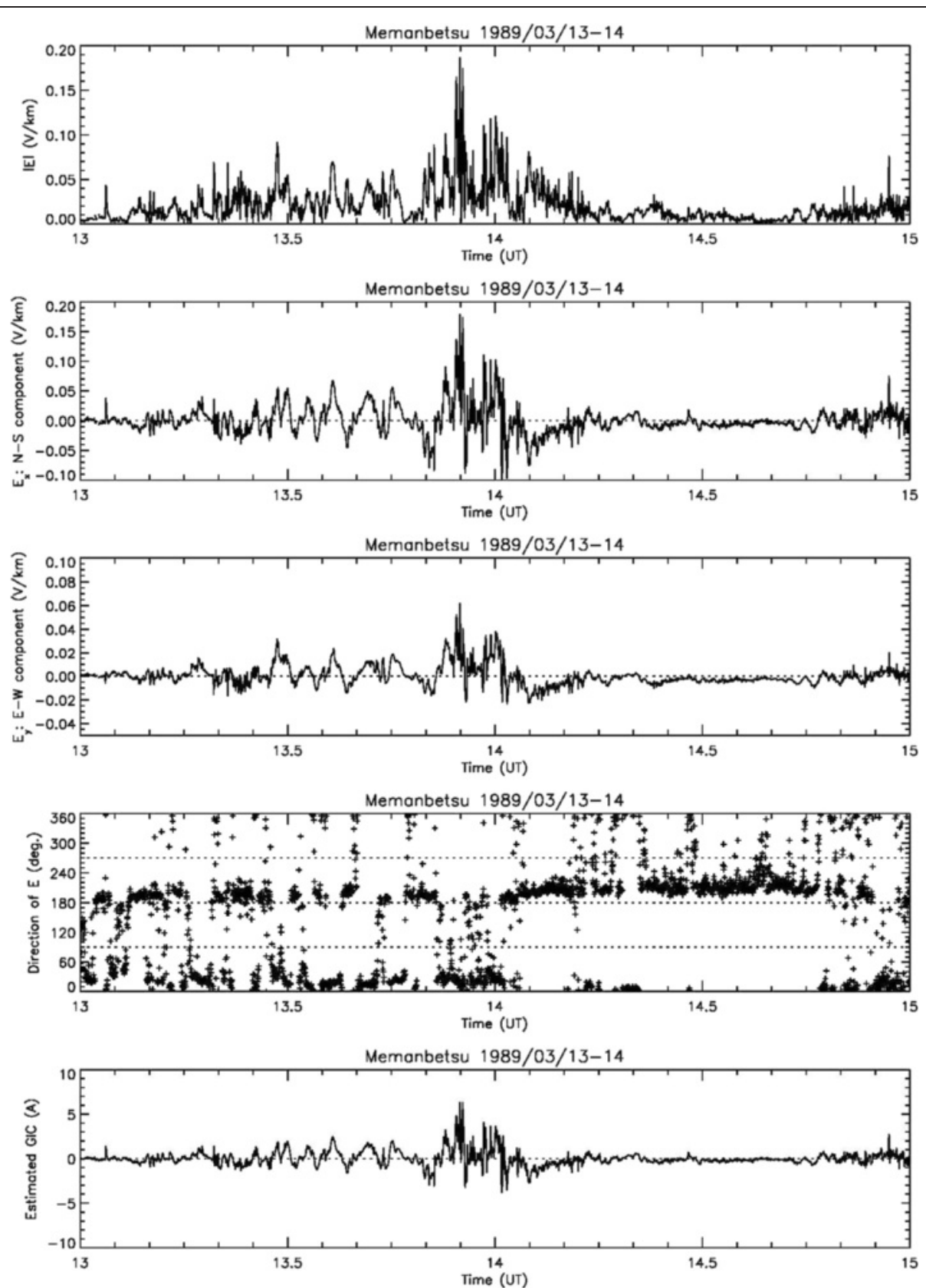

Fig. 10 One-min geoelectric field data observed at the Memanbetsu Observatory of the March 13-15, 1989 storm and the estimated GIC using the 1-min geoelectric field data

components as the equation below (Rikitake and Yokoyama 1953; Gregori and Lanzerotti 1980).

$$
\Delta B_{z}=\alpha \Delta B_{x}+\beta \Delta B_{y}
$$

Parkinson arrow, $(-\operatorname{Re}(\alpha),-\operatorname{Re}(\beta))$ obtained by Eq. 8 is used for analysis of an underground conductivity anomaly. The arrow points direction of conductive layer. Figure 9 shows the values of Parkinson arrow for several frequencies calculated by using geomagnetic field data of
Memanbetsu shown in Fig. 2. According to this figure, Parkinson arrow points eastward. This suggests existence of conductive layer in east of Memanbetsu. Uyeshima et al. (2001) suggested a significant coast effect in eastern Hokkaido based on the observation by the networkmagnetotelluric (network-MT) method. Consideration of underground conductivity is necessary to understand the measured GIC data as a future work.

We calculated GICs of the March 13-15, 1989 storm and the October 29-30, 2003 storm using Eq. 5. 

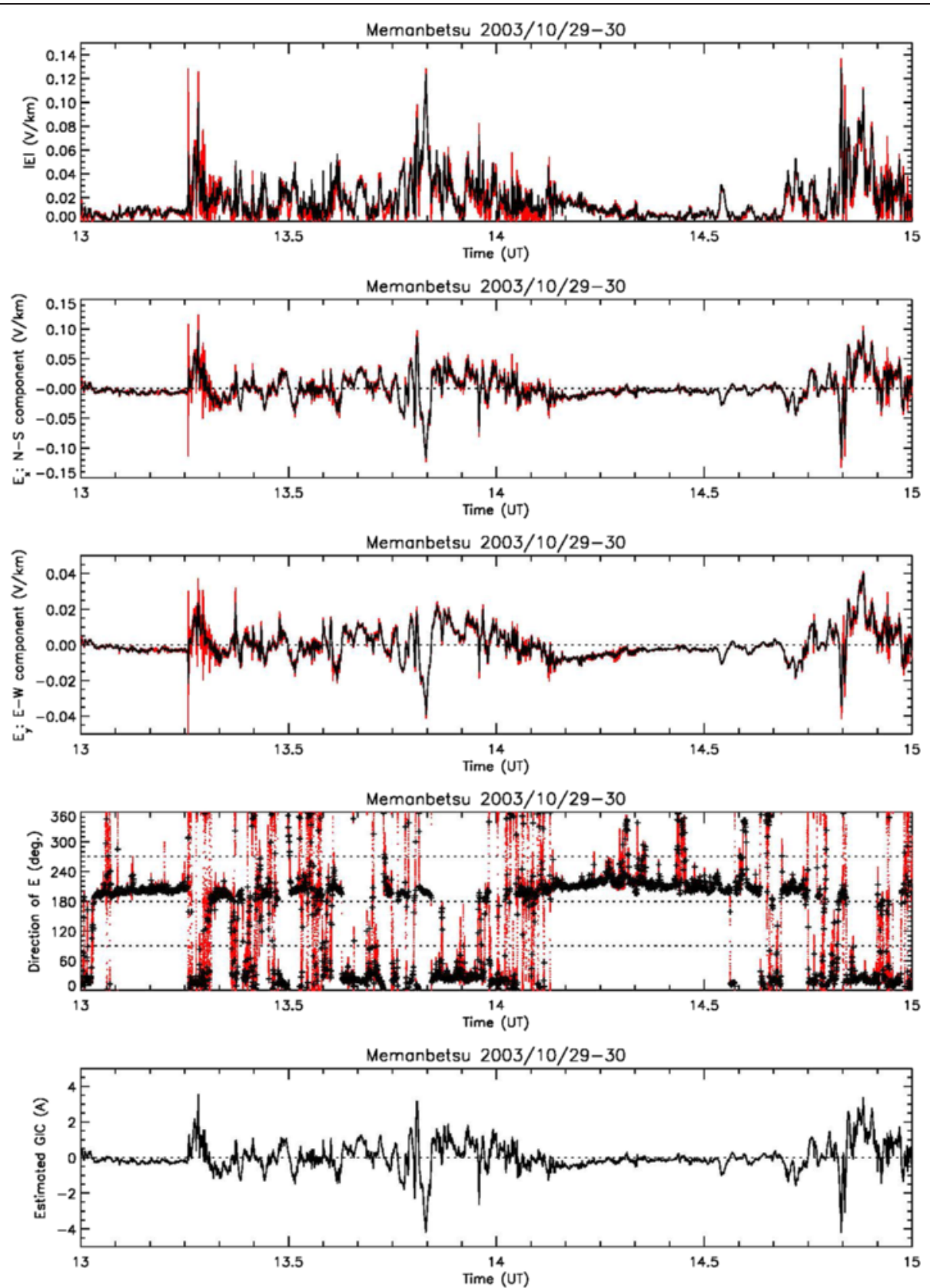

Fig. 11 Geoelectric fields observed at the Memanbetsu Observatory of the October 29-30, 2003 storm and the estimated GIC using the 1-min geoelectric field data. The black lines and crosses show the 1-min data and the red lines and dots in the figure show the 1-s data

Figures 10 and 11 show the electric field data and the estimated GICs using Eq. 5 with the values of $a$ and $b$ obtained from the December 14-15, 2006 event. According to our result, the expected maximum absolute values of GICs are approximately 6.2 and $4.2 \mathrm{~A}$, respectively.

As another approach, GIC is estimated by the equation below (Boteler et al. 1994) for an equivalent circuit of a three-phase electric power line earthed on both ends shown in Fig. 12 when the same earthing resistance, $R_{s}(\Omega)$ and the winding resistance of the transformers $R_{w}(\Omega)$ are assumed for both ends.

$$
\mathrm{GIC}=\frac{E_{\|} L}{\frac{r L+2 R_{w}}{3}+2 R_{s}}=\frac{E_{\|}}{\frac{r}{3}+\frac{2 R_{w}}{3 L}+\frac{2 R_{s}}{L}}
$$

where $E_{\|}(\mathrm{V} / \mathrm{km})$ is the uniform electric field parallel to a power line, $r(\Omega / \mathrm{km})$ is the power line resistance per unit length, and $L(\mathrm{~km})$ is length of the power line. GIC 


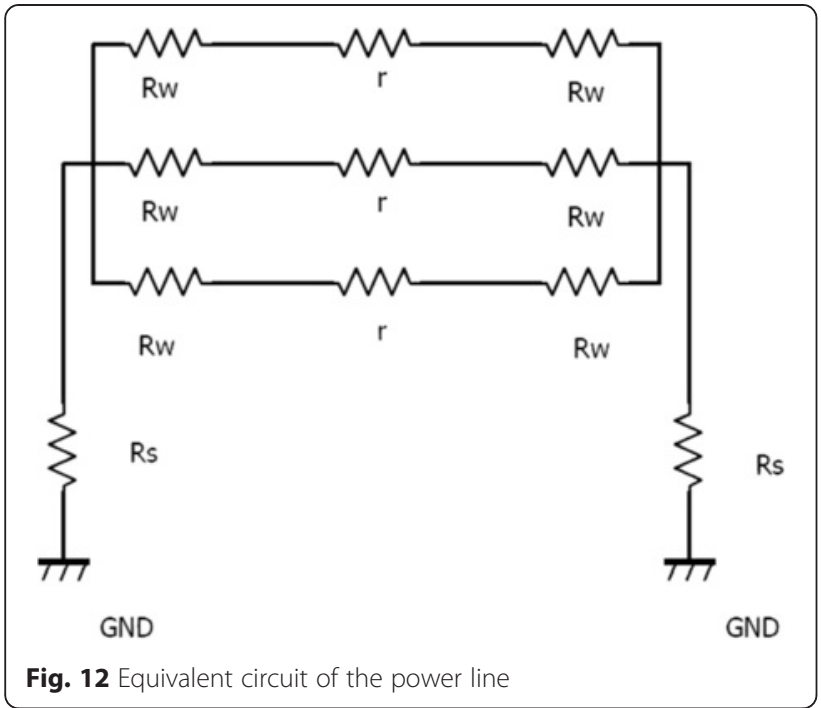

is proportional to electric fields as shown Eq. 9. For the sufficiently long power line, Eq. 9 becomes

$$
\mathrm{GIC} \sim \frac{3}{r} E_{\|}
$$

Equation 10 gives an upper limit of GIC by $E_{\|}$. If we assume that $r$ is $0.05 \Omega / \mathrm{km}$ for $187-\mathrm{kV}$ power lines, $R_{\mathrm{S}}$ is $0.1 \Omega, R_{\mathrm{w}}$ is $0.1 \Omega$, and $L$ is $100 \mathrm{~km}$, Eq. 9 becomes

$$
\mathrm{GIC}=\frac{E_{\|}}{\frac{0.05}{3}+\frac{0.2}{300}+\frac{0.2}{100}} \cong 51.7 E_{\|}
$$

We can estimate GIC using $E_{\|}$as shown in the Eq. 11. According to the result from Eqs. 5, 6, and 7, GIC is also calculated using Eq. 12.

$$
\mathrm{GIC}=\sqrt{a^{2}+b^{2}} E_{\|} \cong 38.8 E_{\|}
$$

Using a DC power source as a proxy of GICs, Takasu et al. (1994) performed experiments on DC excitation for scale models with linear dimensions that were one third to one half of those of actual power transformers. Distortion of wave forms of AC currents was observed by the applied DC currents of several tens ampere to the scale models. A maximum temperature rise of approximately $110^{\circ} \mathrm{C}$ was measured in the case of the core plate and the core support made by magnetic steel for a GIC level of approximately 200 A for three phases. From Eq. 12, the geoelectric field parallel to the power line, $E_{\|}$ of $5.2 \mathrm{~V} / \mathrm{km}$, is necessary for the GIC level of $200 \mathrm{~A}$. We need further studies on GIC levels affecting the power grids to know an effective level of geoelectric fields.

\section{Conclusions}

We studied the GIC data measured at the Memanbetsu substation, Hokkaido, using the geoelectric and geomagnetic field data observed at the Memanbetsu Observatory, JMA, and obtained the empirical equation to estimate GICs associated with the past intense geomagnetic storms. GICs associated with the March 13-15, 1989 storm and the October 29-30, 2003 storm were estimated by using the Eq. 8. Estimated maximum absolute values of the GICs are approximately 6.4 and $4.2 \mathrm{~A}$, respectively. Our estimation seems to be approximately half of the observed values according to the December 14-15, 2006 event shown in Fig. 7. It is necessary to consider the effect of regional underground conductivity for the estimation as a future work. The CCDF of the GIC data is calculated. According to it, the probabilities of extremely large values of the GIC seem to be low. However, it is based on the measurement of approximately 2 years and there is a large uncertainty. We need more long-term data as noted by Hapgood (2011).

\section{Competing interests}

The author declares that he has no competing interests.

\section{Acknowledgements}

The GIC measurements in Hokkaido, Japan, were conducted as part of the close collaboration among NICT, Hokkaido Electric Power Co., and STEL at Nagoya University. We would like to thank the Hokkaido Electric Power Co. for the GIC measurements at the Memanbetsu substation. We thank the Kakiok3a Magnetic Observatory, JMA, for providing us with geomagnetic and geoelectric field data and the lists of magnetic storms at the Memanbetsu Observatory. Finally, we wish to acknowledge the anonymous reviewers and the editor, Dr. Ikuko Fujii, for their valuable comments and suggestions.

Received: 26 October 2014 Accepted: 19 May 2015

Published online: 27 May 2015

\section{References}

Bernabeu EE (2013) Modeling geomagnetically induced currents in Dominoin Virginia power using extreme 100-year geoelectric field scenarios_-part1. IEEE Trans Power Delivery 28(1):516-23. doi:10.1109/TPWRD.2012.2224141

Boteler DH (2001) Space weather effects on power systems. In: Song P, Singer H, Siscoe G (eds) Space weather. AGU, Washington D.C. ISBN 0-87590-984-1

Boteler DH, Shier RM, Watanabe T, Horita RE (1989) Effects of geomagnetically induced currents in the B. C. Hydro $500 \mathrm{kV}$ system. IEEE Trans Power Systems 4(1):818-23

Boteler DH, Bui-Van Q, Lemay J (1994) Directional sensitivity to geomagnetically induced currents of the Hydoro-Quebec $735 \mathrm{kV}$ power system. IEEE Trans Power Delivery 9(4):1963-71

Committee on the Societal and Economic Impacts of Severe Space Weather Events (2008) Severe space weather events-understanding societal and economic impacts: workshop reports. The National Academies Press, Washington D.C. ISBN 0-309-12770-X

Gaunt CT, Coetzee G (2007) Transformer failure in regions incorrectly considered to have low GIC-risk. Paper presented at IEEE Power Tech 2007, Lausanne, Switzerland

Gregori GP, Lanzerotti LJ (1980) Geomagnetic depth sounding by induction arrow representation: a review. Reviews Geophys Space Phys 18(1):203-9

Hapgood MA (2011) Towards a scientific understanding of the risk from extreme space weather. Adv Space Res 47:2059-72. doi:10.1016/j.asr.2010.02.007

Kappenman JG (1989) Effects of geomagnetic disturbances on power systems. IEEE Power Eng Rev 9(10):15-20

Kappenman JG (2004) Effects of space weather on technology infrastructure. In: Daglis IA (ed) Space weather and the vulnerability of electric power grids. Kluwer Academic Publishers, NATO Science Series, pp 257-99. ISBN 1-4020-2747-8

Kappenman JG (2005) An overview of the impulsive geomagnetic field disturbances and power grid impacts associated with the violent sun-earth connection events of 29-31 October 2003 and a comparative evaluation with other contemporary storms. Space Weather 3:S08C01. 10.1029/ 20045W000128 
Kataoka R (2013) Probability of occurrence of extreme magnetic storms. Space Weather 11:1-5. doi:10.1002/swe.20044

Love JJ (2012) Credible occurrence probabilities for extreme geophysical events: earthquakes, volcanic eruption, magnetic storms. Geophys Res Lett 39, L10301. doi:10.1029/2012GL051431

Ogawa Y (2002) On two-dimensional modeling of magnetotelluric field data. Surv Geophys 23(2-3):251-73. doi:10.1023/A:1015021006018

Pulkkinen A, Pirjola R, Viljanen A (2007) Determination of ground conductivity and system parameters for optimal modeling of geomagnetically induced current flow in technological systems. Earth Planets Space 59:999-1006

Pulkkinen A, Bernabeu E, Eichner J, Beggan C, Thomson AWP (2012) Generation of 100-year geomagnetically induced current scenarios. Space Weather 10, S04003. doi:10.1029/2011SW000750

Rikitake T, Yokoyama I (1953) Anomalous relations between $\mathrm{H}$ and $\mathrm{Z}$ components of transient geomagnetic variations. J Geomagn Geoelec 5(3):59-65

Riley P (2012) On the probability of occurrence of extreme space weather. Space Weather 10, S02012. doi:10.1029/2011SW000734

Takasu N, Oshi T, Miyashita F, Saito S, Fujiwara Y (1994) An experimental analysis of excitation of transformers by geomagnetically induced currents. IEEE Trans Power Delivery 9(2):1173-9

The working group on extreme solar weather of the Royal Academy of Engineering (2013) Extreme space weather: impacts on engineered systems and infrastructure. Royal Academy of Engineering, London. ISBN 1-903496-95-0

Thomson A, Reay S, Dawson E (2011) Quantifying extreme behavior in geomagnetic activity. Space Weather 9, S10001. doi:10.1029/2011SW000696

Torta JM, Serrano L, Regue JR, Sanchez AM (2012) Geomagnetically induced currents in a power grid of northeastern Spain. Space Weather 10, S06002. doi:10.1029/2012SW000793

Torta JM, Marsal S, Quintana M (2014) Assessing the hazard from geomagnetically induced currents to the entire high-voltage power network in Spain. Earth Planets Space 66:87. doi:10.1186/1880-5981-66-87

Tsurutani BT, Gonzalez WD, Lakhina GS, Alex S (2003) The extreme magnetic storm of 1-2 September 1859. J Geophys Res 108(A7):1268. 10.1029/ 2002JA009504

Uchida T (1909) Earth current on 25 September 1909. J Inst Electrical Eng Japan 29(255):701-21 (in Japanese)

Uyeshima M, Utada H, Nishida Y (2001) Network-magnetotelluric method and it first results in central and eastern Hokkaido, NE Japan. Geophys J Int 146:1-19

Watari S, Kunitake M, Watanabe T (2001) The Bastille day (14 July 2000) event in historical large sun-earth connection events. Sol Phys 204:423-36

Watari S, Kunitake M, Kitamura K, Hori T, Kikuchi T, Shiokawa K, Nishitani N, Kataoka R, Kamide Y, Aso T, Watanabe Y, Tsuneta Y (2009) Measurements of geomagnetically induced current in a power grid in Hokkaido, Japan. Space Weather 7, S03002. doi:10.1029/2008SW000417

\section{Submit your manuscript to a SpringerOpen ${ }^{\circ}$ journal and benefit from:}

- Convenient online submission

- Rigorous peer review

- Immediate publication on acceptance

- Open access: articles freely available online

- High visibility within the field

- Retaining the copyright to your article

Submit your next manuscript at $>$ springeropen.com 